efficacy of suggestion (persuasion) in hypnosis if he had had the scientific erudition and experience of clinicians like Forel and was master of his subject.

While empirical methods are sufficient in certain cases, many can only be touched by methods based on the special pathology of the discase. But whether or not empirical methods are efficient, it is the aim and object of scientific medicine to investigate the laws of disease and the principles underlying empirical procedures, to the end that the art of treatment may have a rational foundation.

In advocating the introduction of psychopathology into the curriculum of medical schools I ought to state somewhat specifically the field which is intended to be covered. Without attempting to give a definite program, I would suggest the following as a tentative plan. (The classification is not strictly accurate but will serve the purpose.)

Mental physiology. - Mechanism of memory, including physiological (unconscious) memories (spinal cord and ganglia). Meaning of the unconscious. Formation and conservation of unconscious complexes. Meaning of the subconscious and co-conscious. Integrative action of the nervous system. Halbit formation. Emotion. Influence of psychical processes on the functions of the viscera (digestive, vasomotor, secretory, respiratory systems, etc.). Cenesthesia. Hypnosis (theory and phenemena). Suggestion. Idea complexes.

Dissociations of the mind. - Anesthesia. Paralysis. Amnesia. Abstractiorr. Hypnoidal states. Slecp. Trance states. Fatigue. Subconscious ideas and their activity. Unconscious processes. Abulia.

Syntheses. - Sensory automatisms (visual and auditory hallucinations). Paraesthesiae. Pain. Motor automatisms (spasms, contractures). Recurrent mental states. Obsessions. Impulsions. Fixed ideas. Delusions. Unconscious mental complexes and their influences. Dreams.

Spccial pathology. - Neurasthenia. Hysteria. Psychasthenia. Hypochondriasis. Phobias. Habit psychoses and neuroses. Mimicry. Psycholeptic attacks. Recurrent sensorimotor attacks. An!nesic states. Dissociated personality. Fugues. Tics.

Methods of examinations besides the ordinary clinical methods. - Psycho-analysis. tion. Hypnoidization. Hypnosis. writing. Artificial hallucinations. vanic tests. Word reaction tests.

Principles of psychotherapeutics based on psychopathology.

It has been decided to introduce such a course in Tufts College Medical School this year. This, 1 believe, will be the first attempt to give systematic instruction in this subject in a medical school. I regret that it will not be possible to carry out in full even such an incomplete program as I have outlined. 'This is owing to the lack of psychopathic wards to supply the clinical material. To adequately teach psychopathol- ogy, we should have the resources of a hospital at our disposal. Unlike other large cities, there is not a hospital in Boston which provides beds for even a neurological service (if we except the two (!) beds at the Massachusetts General Hospital and the Long Island Hospital). The difficulty of teaching psychopathology without the material which only a hospital afford will be appreciated if one imagines what would be the result to medical education if our teachers of internal medicine and surgery were deprived of their hospital services. However, we propose to take the initiative, relying upon such opportunities for clinical material as may offer, and hoping that either the powers which determine the policies of our hospitals or some good philanthropist will soon provide wards or hospitals in the interest' of patients and of medical science.

\section{Olinital פDepartment.}

\section{CONGENITAL VARICES OF THE RIGHT LEG} AND EXTERNAL GENITAL ORGANS.

BY HARRY W. GOODALI, M.D., BOBTON.

THe following case is of interest on account of its extreme rarity and the slight inconvenience caused by such a marked varicose condition.

Patient: Russian, twenty years old, laborer. Father, mother, two sisters and three brothers living and well. Father states that at birth the physician in attendance said the right arm was around the head. Instrumental delivery after considerable difficulty.

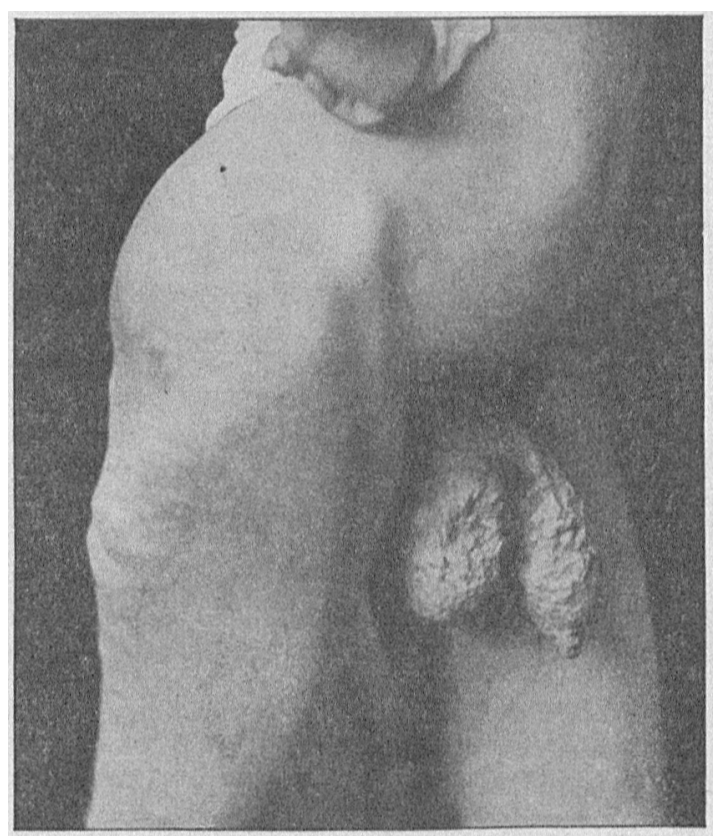

Fig. 1.

At time of birth the whole right side seemed paralyzed, but the right arm and leg were apparently the same size as the left. 'This side remained weak and he was unable to walk at the fourth year. At this time, after taking. the child to several clinics in Russia and 
Germany, systematic massage was begun and the strength gradually increased, but the right side has never been as strong as the left. He walked with at limp for a long time.

The extensive varicose condition described below was present at birth. The extermal genitals were very large. 4 , The father was told at the various elinies that the condition was so extensive operative treatment was inadvisable. When ten years old began to have pain in the right knee and was unable to walk. He was put to bed with the leg suspended for three months. Since then he has had no serious illness and no particular difficulty with the right side.

The patient came to the Boston Dispensary in July, 1908, complaining of slight pain in the left hypochondrium. This was entirely relieved in five days. The varicose condition was discovered in the course of the routine examination.

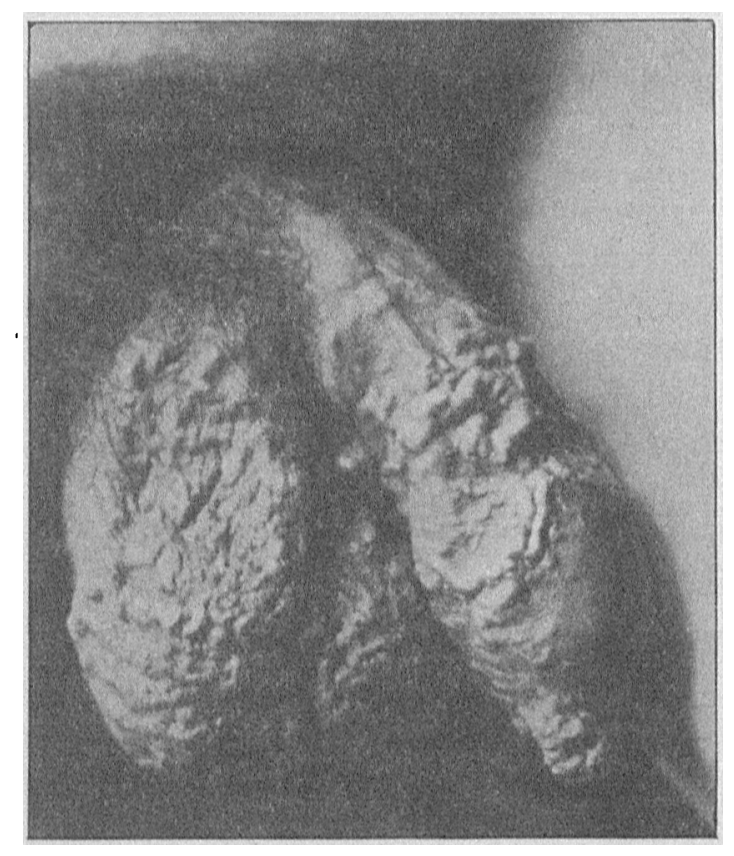

Iig. 2.

His own story is as follows: The external genitals have been as large, the varices as extensive and nearly as pronounced as long as he can remember. There is comparatively little discomfort from the condition. The whole right side is somewhat weaker than the left. Five years ago he worked as a messenger boy, and after walking all day the right side would feel tired. Could ride a bicycle all day without discomfort.

'There has been a slight increase in the discomfort during the past two years. If he stands all day or gets very tired the right side drags somewhat and feels heavy. Any change in weather causes the vessels to enlarge considerably, accompanied by a heavy sensation and slight dragging pains. He has never been obliged to wear a suspensory.

Physical examination: Well developed, muscular. Strength of arms and legs practically equal. Heart, and lungs negative. Abdomen negative except in the region of the right iliac artery just above Poupart's ligament there appears to be a little more thickening of the tissues than on the left: No hemorrhoids. Rectal examination negative. Urine negative.

There is an extensive varicosity of the superficial veins on the posterior surface of the thigh extending from the lower border of the gluteus maximus half way to the popliteal space, forming a venous tumor seren inches long and five inches wide, shown in outline in Fig. 1. From the lower portion of this mass a large varicose veini extends down the posterior surface of the leg, turning around the external malleolus where it forms a second venous tumor practically covering the dorsum of the foot. A similar condition is present in the superficial veins of the external genitals, but is limited to the right half except at the very tip of the foreskin, where it entirely surrounds it. This condition is illustrated in Fig. 2 'There is no varicocele.

The penis with foreskin measures eight inches in length along the dorsum; the circumference just behind the glans is five inches. The serotum is correspondingly large.

'The veins involved are the cxternal saphenous of the leg, branches of the superficial hypogastric and obturator veins supplying the external genitals.

It is apparent that the pathological lesion must he local, as obstruction of a larger vein, such as the femoral, would show a more diffuse cnlargement unless there is some anomaly present.

Holmes ${ }^{1}$ reports a congenital varix of the genitals, but the case is not nearly as extensive as the one just described.

\section{ACU'IE POLIOMYLIIITIS FOLLOWING TONSILLITIS.}

HY KENDALL EMERSON, M.D., WOHCEATEH, MAss., Orthopedic Surgeon to the Memorial Hospital.

THw following case of acute anterior poliomyelitis occurred so soon after a sharp attack of tonsillitis as to suggest the possibility of a common etiology.

R. K., a strong, healthy boy of cight, attended an allday picnic on May 30, $190 \mathrm{~s}$, getting very tired and later thoroughly wet in a shower. The following day he felt badly and went to bed early with a high fever and sore throat. He was slightly delirious during the night. June 1 , his temperature was 104 , pulse 120 , tonsils swollen and showing bright red spots but no membrane, and cervical glands enlarged and tender. A culture of the throat showed a mixed infection with no diphtheria bacilli present. Further study was unfortunately not made of the culture. The boy showed rather extreme toxic symptoms for an ordinary tonsillitis. Under catharsis and a febrifuge he recovered promptly, however, and the next day was up, showing a normal temperature, practically no sore throat and, save that he tired ensily and was cross and irritable, appeared about in his usual health.

June 5, five days after his tonsillitis, he complained in the evening of a curious tingling in his left hand. He slept well and there was no evidence of ferer, though he was not seen by a physician.

June 6, he complained again about the tingling in his left hand and forearm and toward evening his head ached. He played hard during the day and there was no evidence of paralysis or wcakness in the left arm.

June 7 , the left shoulder ached and the headache became severe and extended down into the posterior cervical region. During the afternoon his head became retracted and he appeared feverish. Inin in the left arm was severe and the parents decided he had rheumatism and sent for me. The boy was lying on his

1 Tr. Puth. Soc., 1864, vol, xv,'s. 05. 